\title{
Two-Phase Optimization Method for Determining Distribution Center Locations and Distribution Routes (Case Study: X Ltd.)
}

\author{
Muhammad Rayhan Azzindani, Nabila Fajri Kusuma Ningrum, Mega Rizkah Sudiar, and Anak Agung Ngurah \\ Perwira Redi \\ Department of Logistics Engineering, Universitas Pertamina, Jakarta \\ e-mail:mazzindani@yahoo.co.id
}

\begin{abstract}
One of the main keys to establishing a company's facilities is to determine the best location with consideration of proximity to customers. After determining the location using the P-Center method, the company aims to maximize its profit by minimizing the distribution costs. It can be minimized by finding the shortest route. The best route determination method used in this study is the Capacitated Vehicle Routing Problem. The initial solution was obtained from data processing with the Nearest Neighborhood algorithm. The routes obtained from this method are optimal local results so that they can still be optimized to obtain the optimal global results. The results will be reprocessed with improvement heuristics method, namely Simple Local Search to get the most optimal results. From this data processing, it will produce an output in the form of the location of the best facility and route construction by producing the minimum total of distribution cost.
\end{abstract}

Keywords-CVRP, Logistics Facility Planning, P-Center, Simple Local Search.

\section{INTRODUCTION}

$\mathrm{D}$ ETERMINING the best location is one of the main keys. The accuracy of the choice of company location has a significant direct effect on the success of a company [1]. The location of company placement prioritizes ease in terms of accessibility [2]. In this problem, the company has a goal to maximize service to customer demand. Therefore, accessibility is referred to as accessibility to customers and considering the proximity of the distribution center to the customer (proximity to the customer).

However, location determination is complex. In this issue, there are 12 demand points spread throughout the city. One distribution center must be able to fulfill all demands points within a certain time limit. This specific problem will be solved by the P-Center method. This method was chosen so that the company can reach customers quickly (time-oriented) by minimizing the farthest distance that must be traveled by vehicles to distribute products. P-Center problems are included in NP-hard even if the network is considered to be in a planar condition [3]. If the location selection is not determined with the right calculation, it will hamper the company's performance [4]. (Figure 1)

Several things to consider in this study include the collection of demand points, a collection of candidate points for distribution centers, the coordinates of the location of the demand points, and the number of demands at each demand point. P-Center is a matter of locating facilities at a particular location and obliging to serve all customers by minimizing the farthest distance between each customer point with established facilities [5]. This model is known as the minimax problem because it aims to find the minimum value of the maximum distance value set by each demand point to the distribution center. The data processing is carried out using the AMPL software with an exact final result.

After determining the location of the distribution center, the next step is to plan the distribution route. This problem is a complex matter with 12 demand points, there are more than 200,000 route combinations that are feasible for Vehicle Routing Problem [6]. In general, Vehicle Routing Problem is determining the best distribution route by maximizing the demand points served by the minimum mileage [7]. This method does not consider vehicle capacity, this problem is developed into a Capacitated Vehicle Routing Problem (CVRP). CVRP is a method of determining the efficient route of several vehicles assigned to serve all demands at each point with a limited capacity of the vehicle [8]. Matters considered in this problem include the number of vehicles, the capacity of the vehicle, the coordinates of the location of the demand point, and the number of demands at each demand point. The objective function is mileage minimization. The solution uses a heuristic algorithm. The heuristic algorithm is used to get results quickly and is near-optimal. The methods used include constructive (with the Nearest Neighborhood algorithm) and iterative (with the Simple Local Search method) which are processed in C++ software. The constructive method is used to determine the initial optimal local solution, while the iterative method is used for solution improvement to obtain optimal global results.

\section{OBJECTIVES}

This study aims to determine the best location for the establishment of company facilities, namely the distribution center by considering the proximity to customers to maximize the fulfillment of demand and determine the optimal route by minimizing the company's mileage and distribution costs to get the most efficient product distribution routes.

\section{METHODOLOGY}

This study was carried out in 5 steps. The steps allocation is carried out so that this study is more structured and systematic. Here are the following steps.

\section{A. Data collection}


The 8th International Conference on Transportation \& Logistics (T-LOG 2020)

Surabaya September 6th-7th 2020, Universitas Internasional Semen Indonesia (UISI), Gresik, Indonesia

Table 1.

Coordinates of demand points and distribution center candidates

\begin{tabular}{llll}
\hline \hline ID & Location & Latitude & Longitude \\
\hline 0 & Bekasi Selatan & -6.253160 & 107.007672 \\
1 & Bantargebang & -6.321397 & 106.987680 \\
2 & Bekasi Barat & -6.148609 & 107.047096 \\
3 & Bekasi Timur & -6.261267 & 107.013689 \\
4 & Bekasi Utara & -6.169372 & 107.014173 \\
5 & Jatiasih & -6.293659 & 106.963669 \\
6 & Jatisampurna & -6.359653 & 106.923164 \\
7 & Medan Satria & -6.181190 & 106.973953 \\
8 & Mustikajaya & -6.296519 & 107.034302 \\
9 & Pondok Gede & -6.283940 & 106.909737 \\
10 & Pondok Melati & -6.305366 & 106.932205 \\
11 & Rawalumbu & -6.280534 & 106.994178 \\
\hline \hline
\end{tabular}

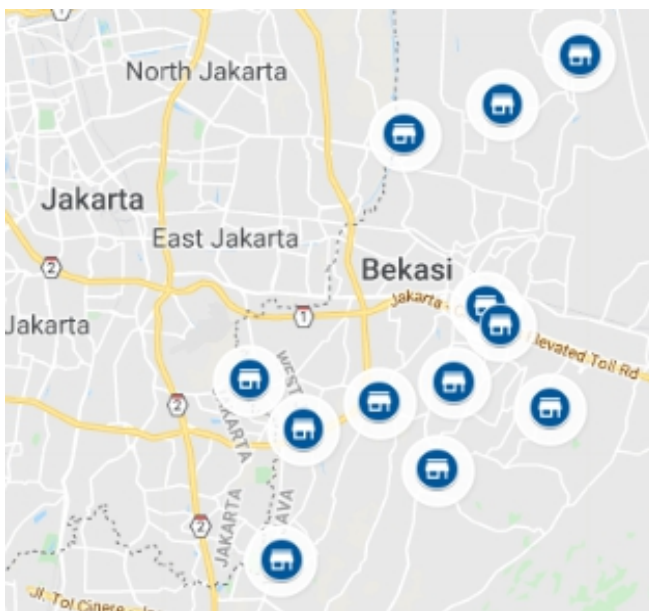

Figure 1. The distribution map of demand points and candidate points for distribution center.

Data collected includes data on the number of distribution center candidates, number of demand points, coordinates of distribution center points, coordinates of demand points, number of demands at each demand point, number of vehicles, and vehicle capacity. The number of vehicles used is 5 units and each vehicle has a maximum carrying capacity of up to 39,200 items. (Table 1 and 2)

B. Determine the Best Location for the Distribution Center Using the P-Center Method with AMPL Software.

The AMPL program is created in a file containing models and data. The model is saved in the .mod file while the data is stored in the dat file. The following is a mathematical model of the P-Center [9].

Set

I : a collection of demand points

$J$ : a collection of distribution center candidates

Input Parameter

$d_{i j}$ : the distance between demand points $i \in I$ and facilities $j \in J$

$h_{i}$ : number of demand at $i \in I$

$P$ : number of facilities to be used

Decision Variable

$X_{j}=\left\{\begin{array}{l}1 \\ 0\end{array}\right.$

: one if you decide to open or use the facility $j \in J$, otherwise it will be zero

$Y_{i j}$ : the fraction of demand at point $i \in I$ that is reached by the facility $j \in J$

$W$ : maximum distance from the demand point to the nearest facility

Model

Minimize W
Table 2.

Coordinates of demand points and distribution center candidates

\begin{tabular}{lll}
\hline \hline ID & Location & Demand per Month \\
\hline 0 & Bekasi Selatan & 9,860 \\
1 & Bantargebang & 23,776 \\
2 & Bekasi Barat & 18,146 \\
3 & Bekasi Timur & 20,350 \\
4 & Bekasi Utara & 30,691 \\
5 & Jatiasih & 20,200 \\
6 & Jatisampurna & 12,076 \\
7 & Medan Satria & 14,916 \\
8 & Mustikajaya & 21,657 \\
9 & Pondok Gede & 24,465 \\
10 & Pondok Melati & 12,730 \\
11 & Rawalumbu & 21,217 \\
\hline \hline
\end{tabular}

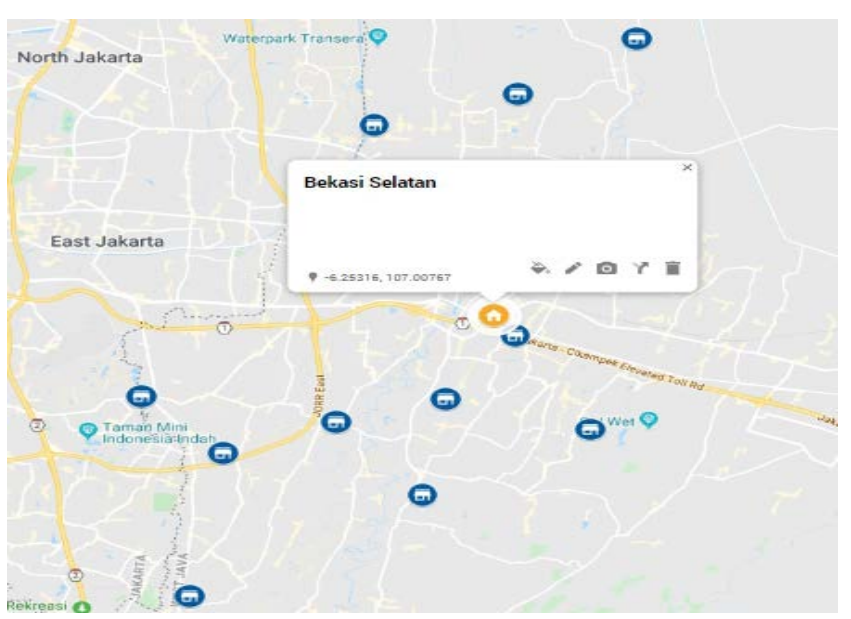

Figure 2. The coordinate point of the distribution center to be built.

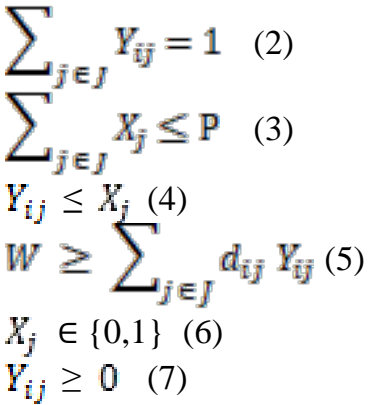

The objective function (1) is to minimize the maximum distance between the demand point and the nearest facility. Constraint (2) requires that all demand at point $i \in I$ must be served by at least one of the facilities. Constraint (3) determines the number of $\mathrm{P}$ facilities that can be used. Constraint (4) ensures that the demand point $i \in I$ is served by facility $j \in J$ if it is selected for use. Constraint (5) is used to determine the distance from the nearest facility to each demand point. This is formulated by determining the maximum value of the distance between the demand point to the facility $(\mathrm{W})$ must be greater than the distance between the demand point $i \in I$ and the facility $j \in J$ used. Constraint (6) and (7) ensure integrality and non-negativity.

C.Determine the route using the constructive method with the Nearest Neighborhood algorithm.

This algorithm functions to produce an initial solution for the iterative algorithm. This algorithm produces optimal local results so that they can be optimized again. Here is the pseudocode of the Nearest Neighborhood.

Input: initial, $\mathrm{N}$, dist $[\mathrm{N}][\mathrm{N}]$

Output: Route [N + 1], obj.

a. Selected [N] initiation to mark all vertices not yet visited / false. 


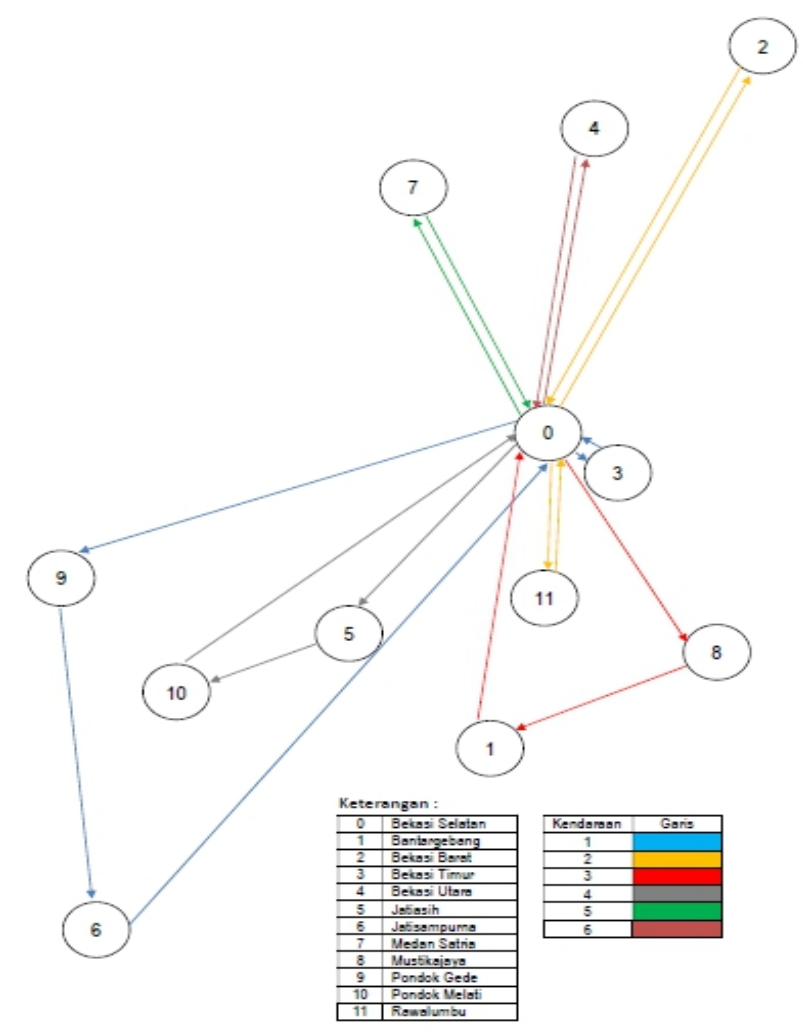

Figure 3. Route results using Nearest Neighborhood algorithm.

Table 3.

Line Color Information

\begin{tabular}{llll}
\multicolumn{4}{c}{ Line Color Information } \\
\hline \hline Vehicle & Color & Vehicle & Color \\
\hline 1 & & 4 & \\
2 & & 5 & \\
3 & & 6 & \\
\hline \hline
\end{tabular}

Vehicle $1: 0 \rightarrow 3 \rightarrow 0 \rightarrow 9 \rightarrow 6 \rightarrow 0$

Vehicle $2: 0 \rightarrow 11 \rightarrow 0 \rightarrow 2 \rightarrow 0$

Vehicle $3: 0 \rightarrow 8 \rightarrow 1 \rightarrow 0$

Vehicle $4: 0 \rightarrow 5 \rightarrow 10 \rightarrow 0$

Vehicle $5: 0 \rightarrow 7 \rightarrow 0$

Vehicle $6: 0 \rightarrow 4 \rightarrow 0$

b. Fill in the value Route [0] = initial, then make the initial value as current. Mark the initial vertex as visited (Selected [initial] = true).

c. Find the shortest distance (nearest) that connects the current vertex with the vertex that has not been visited (next).

d. Calculate obj $=$ obj + dist [current] [next]. Select next as the current vertex position current. Mark next visited (Selected [next] $=$ true).

e. If all vertices have been visited where the last vertex visited was last, return to the initial vertex and calculate obj $=$ obj + dist [last] [initial] then end the algorithm.

If not, return to step 3.

D.Determine the route using the iterative method with the Simple Local Search algorithm.

This algorithm functions to optimize the initial solution which is the optimal local result of the Nearest Neighborhood algorithm. Following is the pseudocode of the Simple Local Search algorithm.

Input: $\mathrm{N}$, dist $[\mathrm{N}][\mathrm{N}]$

Output: BestRoute [N + 1], BestObj.

a. Use the Nearest Neighborhood algorithm to create an initial Route solution [].

b. Set BestRoute [] = Route [] and BestObj = objective

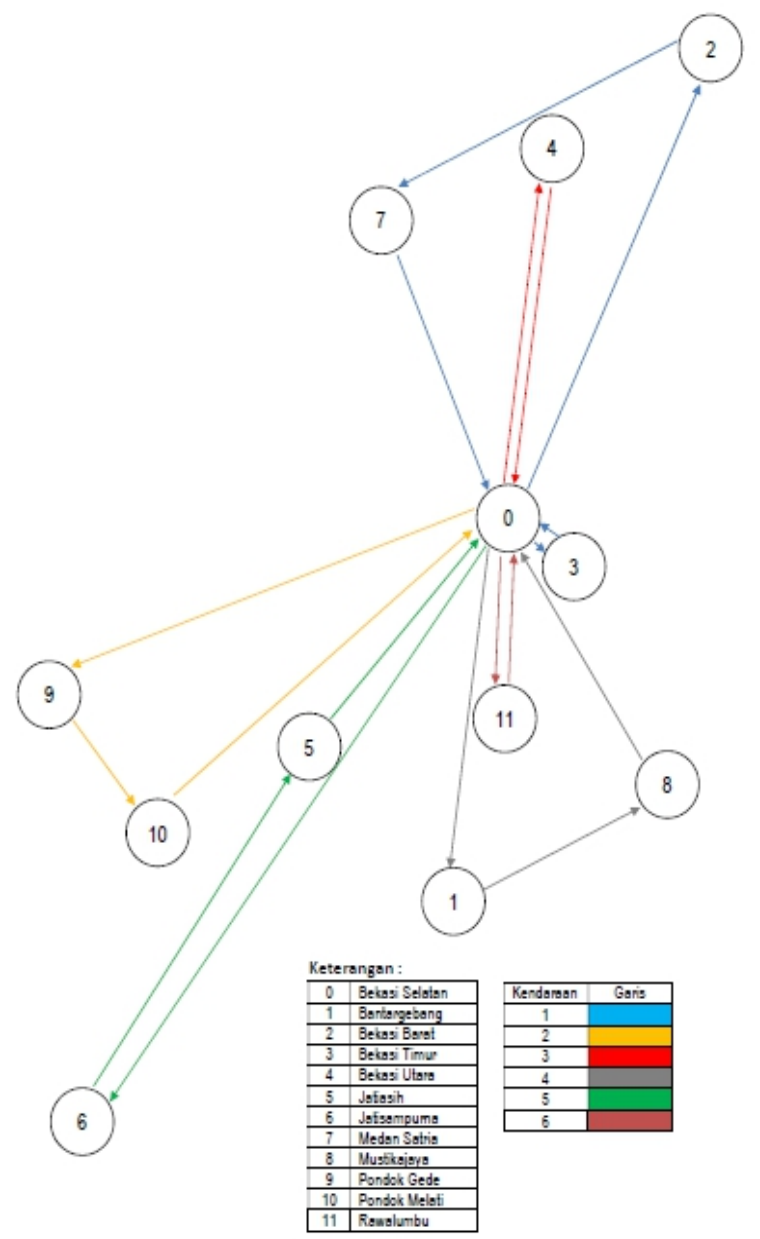

Figure 4. Route results using Simple Local Search algorithm

Vehicle $1: 0 \rightarrow 3 \rightarrow 0 \rightarrow 2 \rightarrow 7 \rightarrow 0$

Vehicle $2: 0 \rightarrow 9 \rightarrow 10 \rightarrow 0$

Vehicle $3: 0 \rightarrow 4 \rightarrow 0$

Vehicle $4: 0 \rightarrow 1 \rightarrow 8 \rightarrow 0$

Vehicle $5: 0 \rightarrow 6 \rightarrow 5 \rightarrow 0$

Vehicle $6: 0 \rightarrow 11 \rightarrow 0$

function values from Route.

c. Use Neighborhood Structure to create a new solution NewRoute [] based on Route [].

d. Calculate Obj = objective function value from NewRoute [].

e. If Obj <BestObj then BestRoute [] = NewRoute [] and BestObj $=$ Obj.

f. If not Route [] = BestRoute []

g. If the termination condition is met then end the algorithm. If not, return to step 3.

$E$. The best objective function available.

After determining the route with the Simple Local Search algorithm, the most optimal results are obtained as the final result of this study.

\section{RESULTS}

Determination of the distribution center by the P-Center method using the AMPL solver obtained the results to build the best distribution center and the results of the objective function, which minimizes the farthest distance that can be traveled from the distribution center to meet all the demands or demands in Bekasi. The results obtained, namely to build the best distribution center in South Bekasi (can be seen in 
Figure 2) with the farthest distance that can be reached by 15 $\mathrm{km}$ and can meet all demands in the city of Bekasi. The farthest distance that can be reached, which is $15 \mathrm{~km}$ which means it is still within reach for its distribution in terms of time and capabilities. So the farthest distance that can be traveled following the tolerance level of the user. In minimizing the cost of distribution center development, it is sufficient to build just one facility so that construction costs become cheaper and more efficient. Then, the greater spread of demand is close to the distribution center in South Bekasi, which means the distribution center considers the proximity to customer aspects. Determination of the distribution center is classified as a strategic problem because the time of decision making is quite a lot and the impact of the resulting decisions also have an impact on the long term. (Figure 2)

After obtaining the distribution center, it is continued to determine the optimal distribution route to meet all demands in the city of Bekasi. By using the Capacity Vehicle Routing Problem (CVRP), the most optimal route design for each vehicle is to carry out the delivery of goods by considering the demand points scattered in an area. Each customer is associated with a demand that needs to be sent to the customer's location. Based on the location of each customer, the distance between these locations and the capacity of the vehicle to transport demand can be known, which is 39,200 items using 6 vehicles. To deliver goods demand, the vehicle is assumed to start the journey from a starting point called a depot or distribution center. By using constructive methods heuristics, the Nearest Neighborhood CVRP algorithm obtained the best route with objective results or the total distance traveled to meet all demands of $146,429 \mathrm{~km}$ as shown on Figure 3 and Table 3.

Based on the Figure 3 and Table 3 results only get optimal local results, because the solution is based on partially built routes based on the criteria for the closest capacity and distance. Then proceed with iterative or improvement heuristics to use the initial solution derived from the Nearest Neighborhood algorithm, then try to improve the solution by finding alternative solutions. It is how to get a better solution than the existing solution. These new solutions are also known as neighborhood solutions because they often have a closeness/similarity to the original solution both in terms of the value of the decision variable/shape/sequence/value of the objective function. The improvement heuristics used are simple local. Obtained objective results or the total distance traveled to meet all demands on Simple Local Search, which is $133,836 \mathrm{~km}$. The results of each vehicle route with a simple local search are as shown on Figure 4.

The results obtained by improvement heuristic are the most optimal results, which is $133,836 \mathrm{~km}$. These solutions are better than existing solutions or Nearest Neighborhood solutions and come out of optimal local results.

\section{CONCLUSION}

Distribution center locations that have been determined by the P-Center method will be established in South Bekasi. The distribution route for finished products using 6 vehicles is as follows: vehicle 1 runs from $0 \rightarrow 3 \rightarrow 0 \rightarrow 8 \rightarrow 1 \rightarrow 0$, vehicle $2: 0 \rightarrow 5 \rightarrow 6 \rightarrow 0$, vehicle $3: 0 \rightarrow 7 \rightarrow 2 \rightarrow 0$, vehicle $4: 0 \rightarrow 11 \rightarrow 0$, vehicle $5: 0 \rightarrow 9 \rightarrow 10 \rightarrow 0$, vehicle $6: 0 \rightarrow 4 \rightarrow 0$. The total distance traveled to complete the route, which is $133,836 \mathrm{~km}$. The resulting solution uses a two-phase optimization method to determine the location of the distribution center and distribution route in the case study X Ltd. is the optimal global solution and the best output.

\section{REFERENCES}

[1] N. Indarti, "Business location and success: the case of internet cafe business in indonesia,” Gadjah Mada Int. J. Bus., 2004.

[2] M. Shidqi, “Analisis penentuan lokasi strategis (studi kasus showroom furnitur di kabupaten jepara),” Libr. Geo Univ. Gadjah Mada, vol. 5, 2016.

[3] H. Calik, "Exact solution methodologies for the p-center problem under single and multiple allocation strategies,” Diss. Dep. Ind. Eng. Grad. Sch. Eng. Sci. Bilkent Univ., 2013.

[4] R. Kumalasari, "Pemilihan lokasi usaha sebagai salah satu strategi dalam business start up,” Binus Univ. Libr., 2017.

[5] D. R.Quevedo-Orozco, "Improving the quality of heuristic solutions for the capacitated vertex p-center problem through iterated greedy local search with variable neighborhood descent in r. z.ríos-mercado,” Comput. Oper. Res., pp. 133-144, 2015.

[6] S. Frederick, Introduction to Operations Research. McGraw-Hill Education, 2014.

[7] R. Nor, "Modeling and simulation of vehicle routing problem based on clustering locations,” Res. Gate, vol. 1, 2016.

[8] A. Slamet, "Vehicle Routing Problem (VRP) dengan algoritma genetika pada pendistribusian sayuran dataran tinggi,” J. Teknol. Ind. Pertan. IPB, vol. 3, 2014.

[9] M. Taghavi and H. Shavandi, "The p-center problem under uncertainty,” J. Ind. Syst. Eng., pp. 48-57, 2012. 